\title{
Damage Tolerance of P/M Turbine Disc Materials
}

\author{
M. Chang ${ }^{*}$, A.K.Koul ${ }^{* *}$, C.Cooper ${ }^{* * *}$ \\ * Dept of Mechanical and Aerospace Engineering, \\ Carleton University, Ottawa, Canada K1S 5B6 \\ ** Structures, Materials and Propulsion Laboratory, \\ Institute for Aerospace Research, \\ National Research Council of Canada, Ottawa, Canada K1A 0R6 \\ *** Chief of Materials, P\&WC, Longueuil, Quebec, Canada J4G 1A1
}

Abstract

The influence of heat treatments on the microstructure and mechanical properties of a powder metallurgy $(\mathrm{P} / \mathrm{M})$ turbine disc alloy MERL76, was studied. A damage tolerant microstructure (DTM) was designed for the alloy using a modified heat treatment (MHT) sequence. Comparisons of mechanical properties between the DTM and the conventional microstructure (CM) were made on the basis of tensile strength, low cycle fatigue (LCF) life, creep rupture life, and fatigue crack growth rates (FCGRs). The DTM significantly improved the creep rupture life $\left(\approx 10\right.$ times) at $760^{\circ} \mathrm{C}$ but resulted in a marginal loss. in tensile strength. The FCGR tests showed that FCGRs of the DTM at $700^{\circ} \mathrm{C}$ were much lower than the CM material by a factor of 10 at a frequency of $0.15 \mathrm{~Hz}$ whereas the FCGRs at a frequency of $1 \mathrm{~Hz}$ were comparable over a wide range of $\Delta K$ values. The $\mathrm{LCF}$ lives of the two microstructures at $700^{\circ} \mathrm{C}$ were also comparable.

Introduction

The United States Air Force (USAF) military standard MILSTD-1783 [1], for new jet engine design and MIL-STD-1843 [2] for engine maintenance, demand that both crack initiation life as well as damage tolerance requirements for critical components such as turbine discs must be satisfied. Designing microstructures which satisfy damage tolerance requirements as well as crack initiation life at all fracture critical locations over a wide range of temperatures is a challenging task.

A damage tolerant microstructural design philosophy for turbine disc materials has been previously developed $[3,4]$ with a view to improving thcir creep properties and elevated temperature fatigue crack growth resistance without sacrificing tcnsile strength and LCF crack initiation life relative to the conventional microstructure (CM). This philosophy was used to develop a damage tolerant microstructure (DTM) for Alloy 718 [3-5] and later other workers [6,7] extended this philosophy to $\mathrm{P} / \mathrm{M}$ turbine disc materials such as René $88 \mathrm{DT}$ and N18. This microstructural design philosophy relies on super-solvus

$$
\text { Superalloys } 1996
$$

Edited by R. D. Kissinger, D. J. Deye, D. L. Anton,

A. D. Cetel, M. V. Nathal, T. M. Pollock, and D. A. Woodford

The Minerals, Metals \& Materials Society, 1996 processing of the disc materials coupled with a strict control of microstructural features such as the grain size, grain boundary morphology, grain boundary carbides distribution, $\gamma^{\prime}$ precipitate distribution and dislocation sub-structures [8].

This paper examines the possibility of applying this philosophy to P/M MERL76 turbine disc alloy and developing a damage tolerant microstructure (DTM) for this material. Influence of the DTM on elevated temperature mechanical properties is studied and the results are compared with the $\mathrm{CM}$ properties.

\section{Test Materials and Methods}

A Gatorized ${ }^{1}$ MERL76 turbine dise forging was used in this study and the forging conformed to the following chemical composition (wt.\%):

$\begin{array}{ccccccccccc}\mathrm{Cr} & \mathrm{Co} & \mathrm{Mo} & \mathrm{Al} & \mathrm{Ti} & \mathrm{Nb} & \mathrm{Hf} & \mathrm{C} & \mathrm{B} & \mathrm{Zr} & \mathrm{Ni} \\ 12.2 & 18.3 & 3.2 & 5.0 & 4.3 & 1.4 & 0.4 & 0.02 & 0.02 & 0.06 & \text { bal. }\end{array}$

The $\mathrm{CM}$ is produced through the standard heat treatment (SHT) sequence of solutioning at $1143^{\circ} \mathrm{C} / 2 \mathrm{hr} / \mathrm{OQ}$ followed by stabilization at $982^{\circ} \mathrm{C} / 1 \mathrm{hr} / \mathrm{Fan}$ Air Cool and aging at $732^{\circ} \mathrm{C} / 8 \mathrm{hr} / \mathrm{AC}$. A modified heat treatment $(\mathrm{MHT})$ was designed to produce the DTM through supersolvus solutioning above $1190^{\circ} \mathrm{C}$ followed by the same aging sequence. The stabilization treatment, which is used for stabilizing the primary $\gamma^{\prime}$ size in the SHT, was however dropped in the MHT because the specimens are furnace cooled after the solutioning treatment and this slow cooling also has a stabilizing effect on primary $\gamma^{\prime}$. The DTM has a coarser grain size (ASTM 7) relative to the SHT matcrial (ASTM 11) and it also contains a serrated grain boundary structure which was produccd through the precipitation of $\gamma^{\prime}$ phase along the grain boundaries. The intragranular $\gamma^{\prime}$ distribution was also modified in the DTM.

A series of mechanical tests was performed on both $\mathrm{CM}$ and

1 Gatorizing involves hot extrusion of powder metallurgy material followed by isothermal forging. 
DTM, as described below.

Creep Rupture Test specimens, conforming to standard ASTME8 and E139 specifications, were tested in air at $760^{\circ} \mathrm{C}$ using a constant load which resulted in an initial stress of $350 \mathrm{MPa}$. Temperature was controlled to within $\pm 1^{\circ} \mathrm{C}$. Two creep specimens each were tested per heat treatment condition.

Tensile Tests, on specimens conforming to ASTM-E8 and E21 specifications, were conducted at RT and $700^{\circ} \mathrm{C}$. The test strain rates were of the order of $3.7 \times 10^{-4} \mathrm{~s}^{-1}$ and $3.7 \times 10^{-5} \mathrm{~s}^{-1}$ in $700^{\circ} \mathrm{C}$ and room temperature tests respectively. Temperature was controlled to within $\pm 2^{\circ} \mathrm{C}$,

Fatigue erack growth rate (FCGR) tests at $700^{\circ} \mathrm{C}$ were conducted in air on compact tension (CT) specimens, conforming to ASTM-E647 specifications, at frequencies of $1,0.25$, and 0.15 $\mathrm{H} z$ using a trapezoidal waveform and a stress ratio $R=0,1, \mathrm{~A}$ maximum load of $6-7 \mathrm{kN}$ was used, which produced a stress intensity range $A K$ in the range of 10 to $100 \mathrm{MPa} \sqrt{\mathrm{m}}$. A direct current potential drop (DCPD) technique, using a current of 20 ampere, was used to monitor crack propagation. Pre-cracking was carried out with load-shedding from $11 \mathrm{kN}$ down to $7 \mathrm{kN}$ in 4 steps at $700^{\circ} \mathrm{C}$ and $1 \mathrm{~Hz}$. Three CT specimens were tested for each microstructural condition.

LCF Tests on smooth axial cylindrical low cycle fatigue specimens $(07.62 \times 25.4 \mathrm{~mm})$, conforming to ASTM-E606 specifications, were conducted in air at $700^{\circ} \mathrm{C}$ under strain control using a triangular waveform and fully reversed $(R=-1)$ loading at a constant strain rate of $0.002 s^{\prime}$. The tests were conducted over a total strain range of $0.9-2.0 \%$. Crack initiation life was defined as the number of fatigue cycles required to create a $5 \%$ drop in the steady state stress value. Three to five specimens at each strain range level were tested for each microstructural condition.

\section{Results and Discussion}

The conventional microstructure of MERL 76 after the standard heat treatment is shown in Fig-1, Large blocky pits are ' $\gamma$ ' particles or $\gamma^{\prime}$ grains with interphase boundaries (IPBs) which were etched out as a result of etching in Kalling's reagent 2 These large $\gamma$ ' precipitates with IPBs contribute little to the strength of the ' $\gamma^{\prime}$ strengthened superalloys. It has been recognized that, during superalloys processing, super-solvus solution treatment for high $\gamma^{\prime}$ volume fraction $(-40 \%)$ alloys should be selected in a manner such that the temperature is high enough to dissolve all $\gamma^{\prime}$ but at the same time excessive grain growth must be prevented in order to achieve a balance between tensile strength, creep, and fatigue properties $[8,9]$.

Grain coarsening characteristics of MERL 76 as a function of solution treatment temperatures and times are shown in Fig-2. Two grain coarsening temperatures (GCTs) were observed at $1185 \sim 1190^{\circ} \mathrm{C}$ and $1235-1250^{\circ} \mathrm{C}$. This behaviour is known to occur in Ni-base P/M superalloys with micro-duplex $\gamma-\gamma^{\prime}$

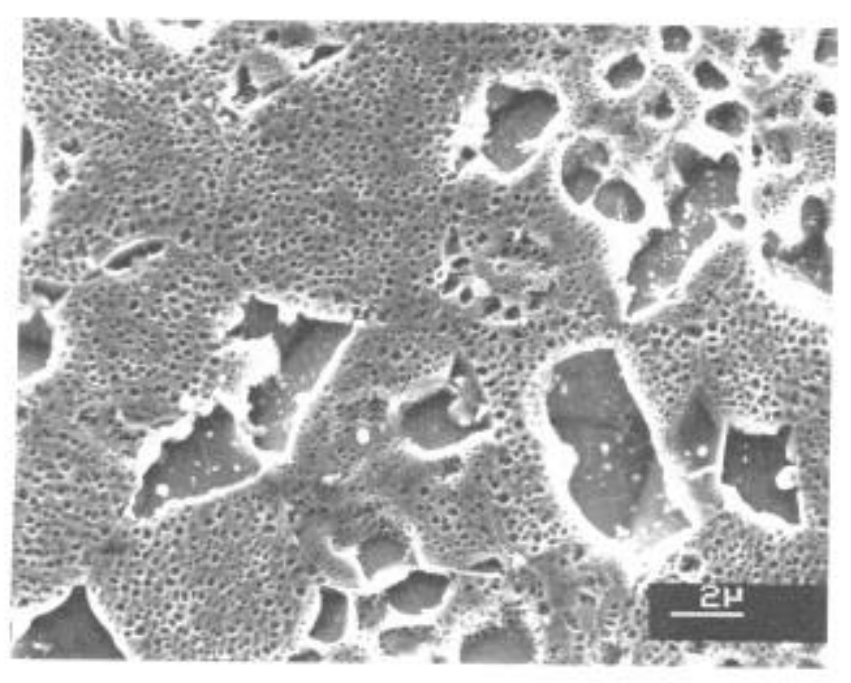

Fig-1. Conventional microstructure (CM) of P/M MERL76.

microstructures containing high $\gamma$ ' volume fraction with IPBs [8] It is believed that the two GCTs are associated with the $\gamma$ and primary MC carbides solvus temperatures. The $\gamma^{\prime}$ solvus temperature of MERL.76 is about $1188-1191^{\circ} \mathrm{C}$ [10-12], depending on the Hf content, which matches the first GCT in Fig-2. The MC carbides solvus temperature of MERL76 is not well documented in the open literature. However, it was reported that, in a high-carbon $(0.17)$ P/M IN100 (MERL76 is a low carbon derivative of $\mathrm{P} / \mathrm{M} \mathrm{IN} 100$ ), the $\mathrm{MC}$ solvus is about $1260^{\circ} \mathrm{C}$ $[8,20]$. Because of the low carbon content, the amount of $\mathrm{MC}$ carbides in MERL76 should be lower and the grain coarsening therefore starts at a lower temperature relative to the MC carbide solvus temperature of $\mathrm{P} / \mathrm{M}$ IN100.

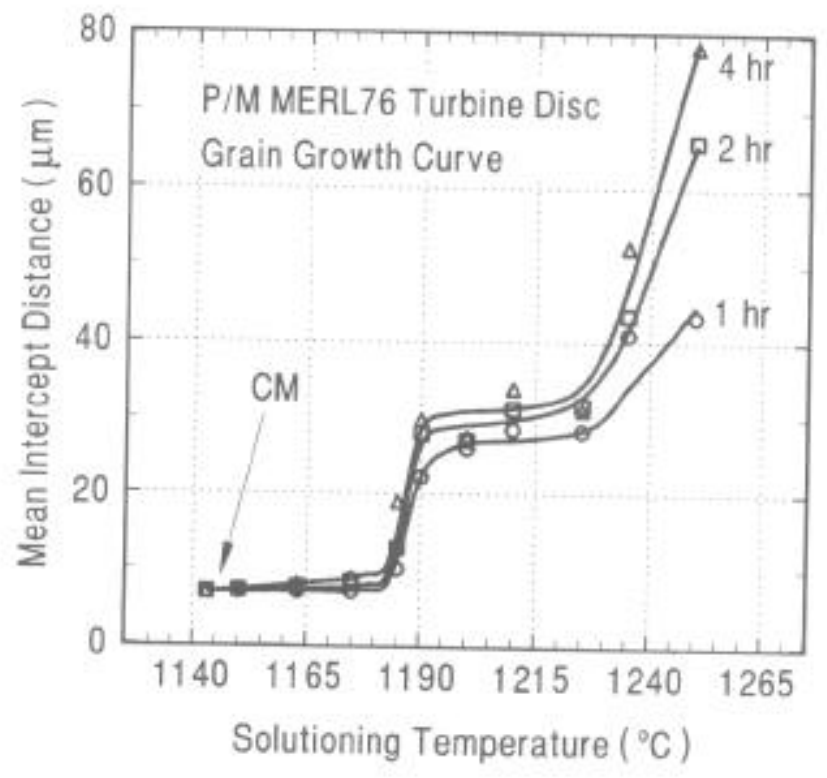

Fig-2. Grain coarsening characteristics of P/M MERL76. 
At temperatures above $1185^{\circ} \mathrm{C}$ some porosity $(<0.1$ vol.\%) was also observed. It is not clear whether these pores form as a result of $\gamma$ particles with IPBs being etched out or condensation of argon gas into bubbles during elevated temperature solutioning. Above $1210^{\circ} \mathrm{C}$, evidence of intergranular incipient melting was observed by SEM. Evidence of incipient melting temperature (IMT) as low as $1196^{\circ} \mathrm{C}$ has been reported for this alloy [13]. The temperature window between the $\gamma^{\prime}$ solvus and the grain boundary IMT in this alloy is narrow, compared to other disc alloys in Table-1, because of the presence of high levels of $\mathrm{Hf}, \mathrm{B}$, and $\mathrm{Zr}$ which are well known melting point depressants. For example, at $0.4 \% \mathrm{Hf}$ the IMT is $1207^{\circ}$ while at $0.7 \% \mathrm{Hf}$ it is only $1196^{\circ} \mathrm{C}[11]$

In spite of the small temperature window, super-solvus processing for this alloy is still possible if the temperature distribution can be well controlled. In P/M alloys, the temperature window between $\gamma^{\prime}$ solvus and incipient melting should be large enough, to allow for super-solvus processing. After super-solvus solutioning, it is necessary to control the subsequent $\gamma^{\prime}$ precipitation along the grain boundaries to form serrated grain boundaries and intragranular matrix $\gamma^{\prime}$ precipitate size and distribution to optimize properties.

Table-1. The $\gamma^{\prime}$ solvus, GCT, IMT $\left({ }^{\circ} \mathrm{C}\right)$ in turbine disc alloys

\begin{tabular}{lcccc}
\hline \hline \multicolumn{1}{c}{ Alloy } & $f(\%)$ & $\gamma$ solvus & GCT & IMT \\
\hline MERL76 [10,11] & 64 & 1190 & 1180 & 1196 \\
IN100 [10,20] & 61 & 1185 & 1200 & 1260 \\
N18 [7,10] & 55 & 1190 & 1140 & $>1200$ \\
AF115 [14] & 55 & 1190 & $\ldots$ & $>1200$ \\
Rene95 [10,15] & 48 & 1155 & 1175 & $>1190$ \\
Astroloy [10,16] & 45 & 1145 & 1130 & 1220 \\
\hline
\end{tabular}

$f=\gamma^{\prime}$ volume fraction; $\mathrm{GCT}=$ grain coarsening temperature; IMT = incipient melting temperature.

Solutioning time has no significant effect on the grain size of the alloy in the temperature ranges of $1150^{\circ} \mathrm{C}-1180^{\circ} \mathrm{C}$ and $1190^{\circ} \mathrm{C} \cdot 1225^{\circ} \mathrm{C}$, But between $1180^{\circ} \mathrm{C}-1190^{\circ} \mathrm{C}$ (the first GCT), however, longer solutioning time ( 4 hours) results in a larger average grain diameter $(19 \mu \mathrm{m})$ than shorter solutioning time ( 2 hours, $13 \mu \mathrm{m}$ ). Solutioning at $1190^{\circ} \mathrm{C}$ for 2 or 4 hours produces similar grain sizes. This suggests that solutioning time should be about 2 hours if solution temperatures above $1190^{\circ} \mathrm{C}$ but below $1225^{\circ} \mathrm{C}$ are used. For comparison, one sample was treated at $1185^{\circ} \mathrm{C} / 7 \mathrm{hr} / \mathrm{AC}$ to check the effect of a very long solution time on grain growth. The result showed that the grain size was similar to that observed after 2 hours of solutioning. However, very large $\gamma^{\prime}$ grains were reduced in number with the longer solution time of 7 hours and the grains were more uniformly distributed. When solution temperatures are highet

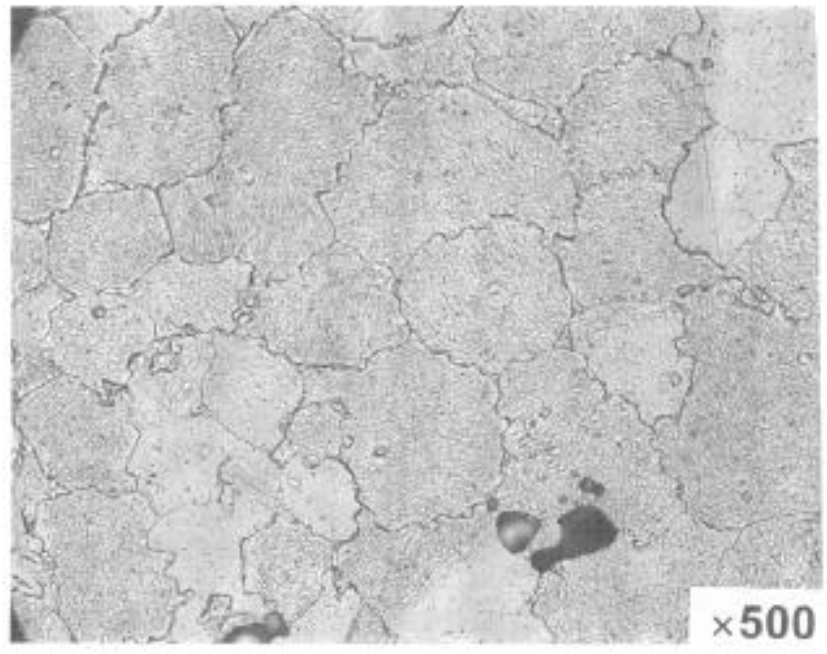

Fig-3. Serrated grain boundaries in MERL76.

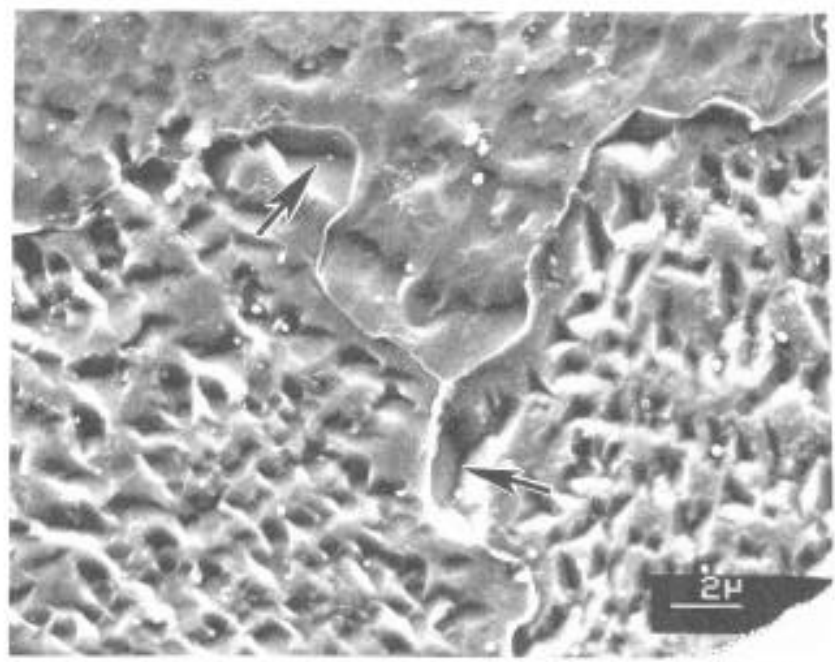

Fig-4. Almost elliptical $\gamma^{\prime}$ (arrows) precipitated along the grain boundaries form the serrations.

than $1225^{\circ} \mathrm{C}$, the grain growth is rapid and solution time has a very strong effect on grain growth. Therefore, depending on the material heat and its incipient melting temperature, the supersolvus solution temperature must be strictly controlled over a range of 1180 to $1205^{\circ} \mathrm{C}$ for dissolving all $\gamma^{\prime}$ including $\gamma^{\prime}$ with IPBs.

Serrated grain boundaries in MERL76 can be successfully generated simply through furnace cooling from super-solvus solution temperature, Figs 3 and 4. All large angle grain boundaries are serrated. The relatively lower misoriented and twin boundaries, about $10 \%$ of the total grain boundaries, are not changed into a serrated morphology. These results are not totally unexpected because the grain boundary ' $r$ - matrix misfit in this alloy is large enough to provide the necessary driving force for the formation of serrations along high angle boundaries $[17,18]$. 
The $\gamma^{\prime}$ morphology and size distribution of super-solvus solutioned and furnace cooled plus aged $\left(732^{\circ} \mathrm{C} / 8\right.$ hours) specimen, i.e. DTM specimen, are compared with the $\gamma^{\prime}$ morphology and size distribution in the conventional microstructure (CM) in Fig-5. The $\gamma^{\prime}$ size, morphology, and distribution are considerably different in the two microstructures. The CM contains micro-duplex $\gamma-\gamma^{\prime}$ grain structure where the $\gamma^{\prime}$ grains with IPBs are up to $6 \mu \mathrm{m}$ in diameter. The $\mathrm{CM}$ also contains coarse intragranular primary and secondary $\gamma^{\prime}$ precipitates. In contrast, the DTM contains grain boundary $\gamma^{\prime}$ along each valley and peak of the serrated grain boundaries. Fig4 and a uniform distribution of intragranular primary $\gamma^{\prime}$ with rosette morphology and a finer secondary $\gamma^{\prime}$ size, Fig-5(b).

Monotonic tensile properties of the two microstructures are compared in Fig-6. The DTM lowers the yield strength marginally by $-7 \%$ and the UTS by $16 \%$ relative to the CM at room temperature. Tensile ductility of the DTM material is about $15 \%$ relative to $22 \%$ observed in the case of the $\mathrm{CM}$. The presence of a coarser grain size in the DTM could have
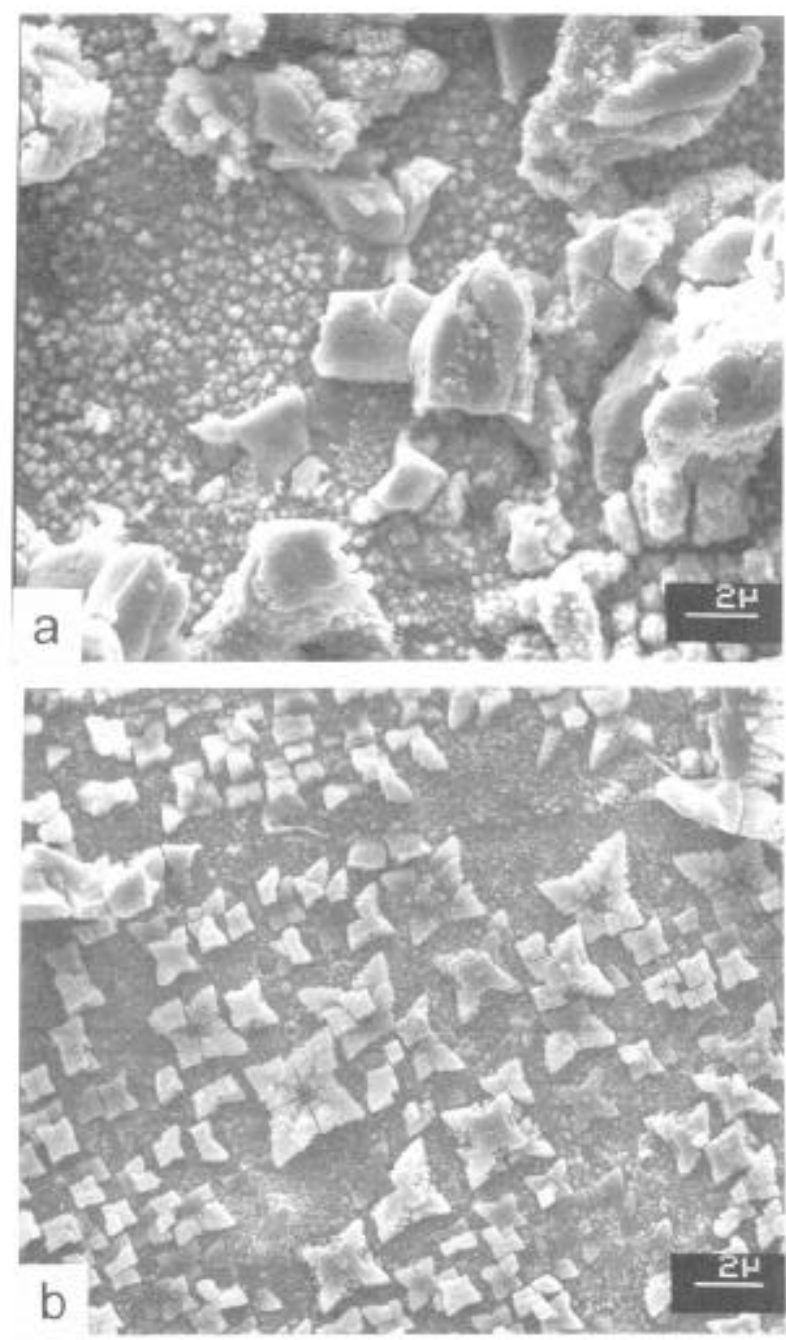

Fig-5. The $\gamma^{\prime}$ morphology in (a) CM and (b) DTM. contributed towards the decrease in yield strength at room temperature through the well known Hall-Petch effect. At $700^{\circ} \mathrm{C}$, however, the tensile strength is about the same for both microstructures but the yield strength is reduced by $7 \%$ relative to the $\mathrm{CM}$. The difference in tensile ductility may also be influenced by, other than the Hall-Petch effect, the presence of porosity in the DTM. The difference in room temperature hardness values between the two materials (46.5 HRC for CM and 44.5 HRC for DTM) is consistent with the trends in yield strength results. The elastic modulus of the DTM is marginally higher than that of the $\mathrm{CM}$ at both test temperatures.

Tensile fracture of the two microstructures at room temperature and $700^{\circ} \mathrm{C}$ is quite different. At room temperature, the $\mathrm{CM}$ specimen revealed a mixture of intergranular and transgranular fracture. The transgranular part is associated with the fracture of the large $\gamma^{\prime}$ grains with IPBs. At $700^{\circ} \mathrm{C}$, the $\mathrm{CM}$
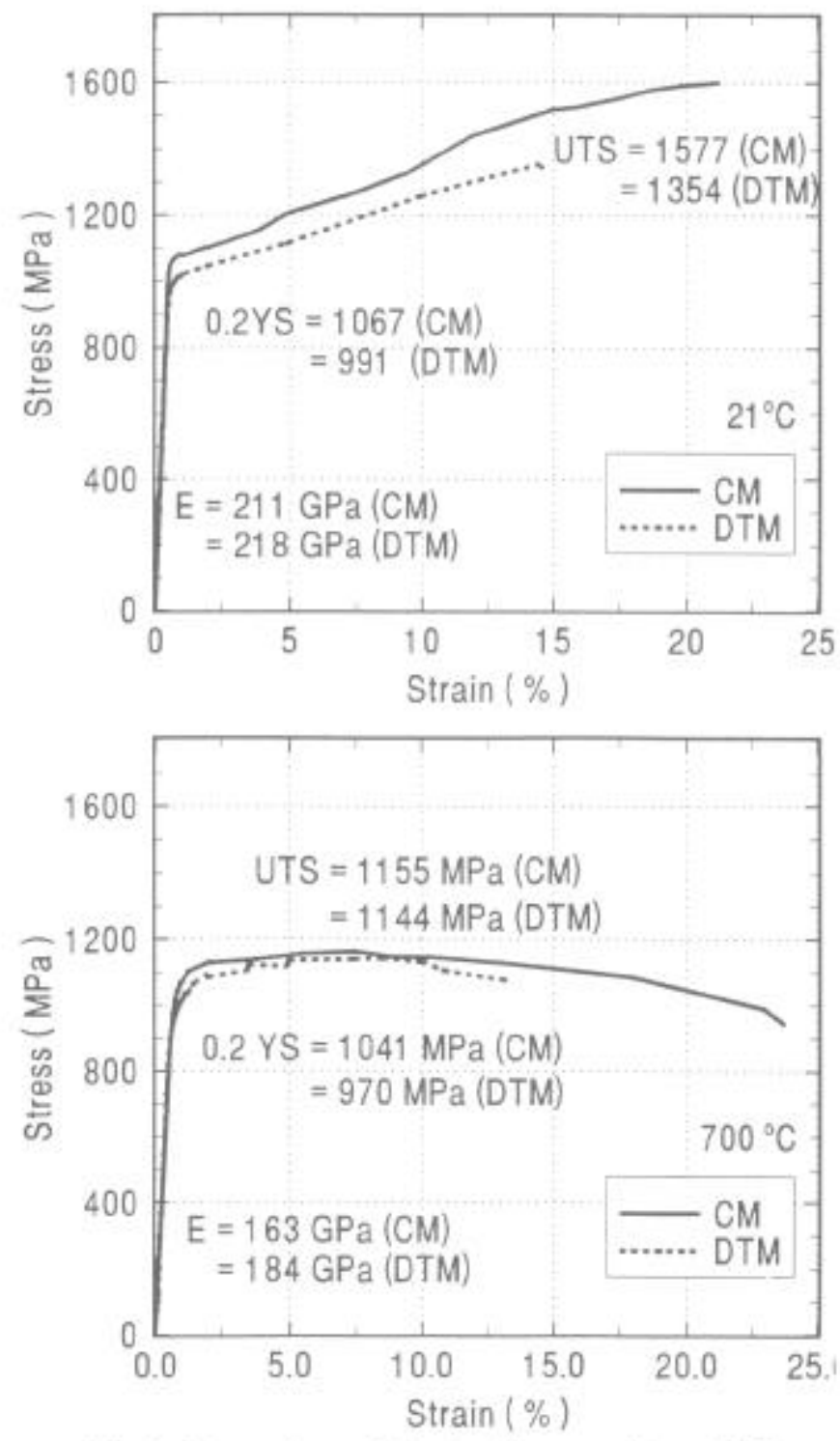

Fig-6. Comparison of the tensile properties of $\mathrm{CM}$ and DTM at room temperature and $700^{\circ} \mathrm{C}$. 
fractures intergranularly and many secondary intergranular cracks are also present. The DTM material, on the other hand, is characterized by a mixed mode fracture at both room and elevated temperatures, Fig- 7 .

Owing to the hardness difference between the matrix and the large $\gamma^{\prime}$ particles in the CM. deformation is not evenly distributed, stress builds up at IPBs and fractures the $\gamma^{\prime}$ grains. The large $\gamma$ particles are probably sheared due to their brittle character at lower temperatures. As temperature increases, the grain boundaries become the weak link in the overall structure and this is why the fracture mode in the $\mathrm{CM}$ at $700^{\circ} \mathrm{C}$ is predominantly intergranular. This transition in fracture mode also indicates that the grain boundaries of MERL76 need to be strengthened for elevated temperature applications. At lower as well as elevated temperatures, the IPBs between the matrix and large $\gamma^{\prime}$ particles provide the readily available crack initiation sites, In the case of the DTM. however, the serrated grain boundaries re-distribute and lower the stresses along the grain boundaries and promote the transgranular deformation.
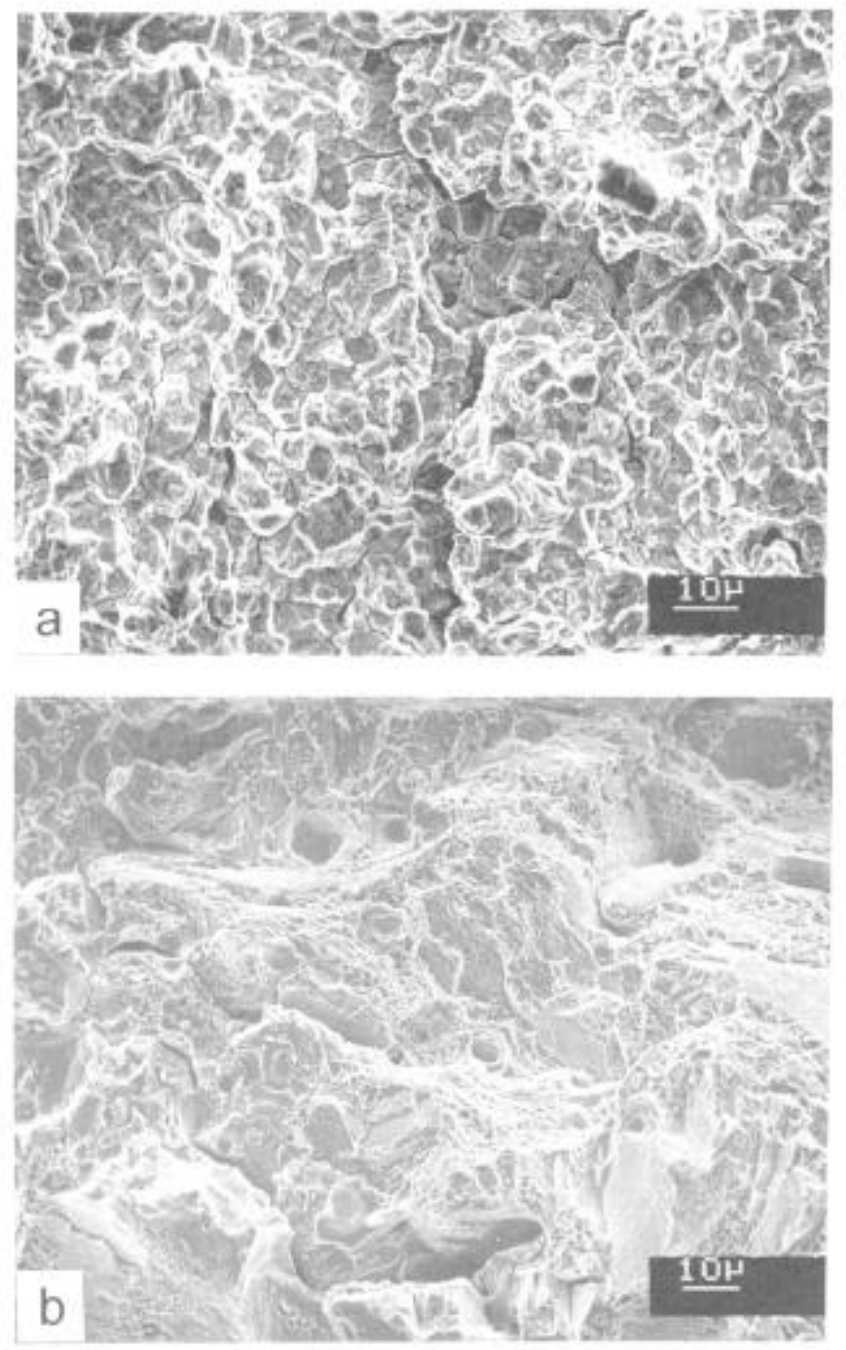

Fig-7. Tensile fracture of CM (a) and DTM (b) at $700^{\circ} \mathrm{C}$.

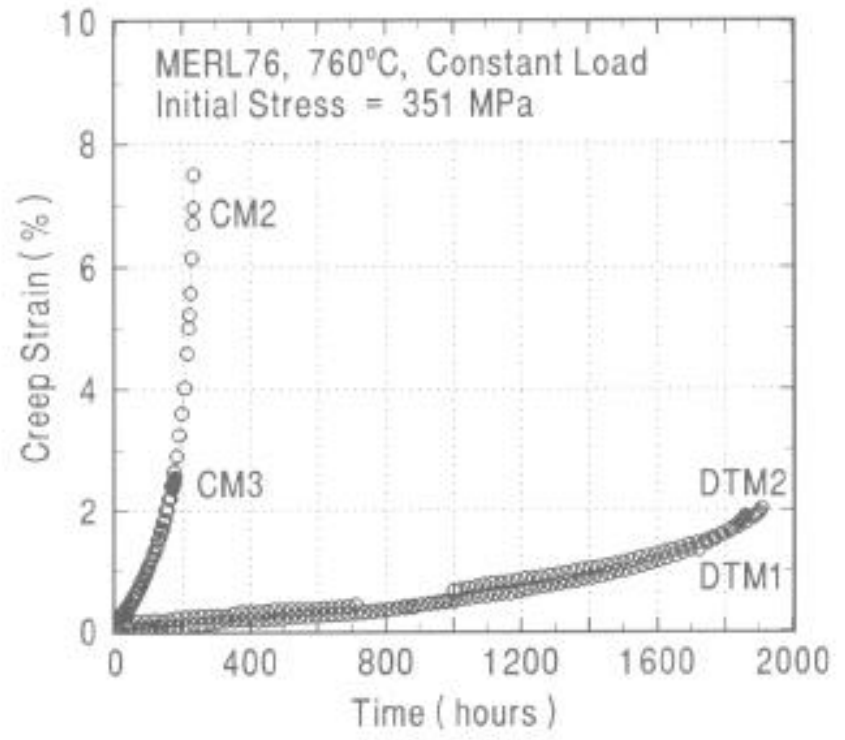

Fig-8. Creep rupture comparison of DTM and CM at $760^{\circ} \mathrm{C}$ and $350 \mathrm{MPa}$.

The DTM substantially improved the creep rupture life of MERL 76, Fig-8, by a factor of 9 and reduced the minimum creep rate by a factor of 20 relative to the $\mathrm{CM}$. The rupture strain in the DTM was lower. It is evident that the improvement in DTM creep rupture life occurs as a result of an extended secondary stage of creep and the loss in creep ductitity occurs as a result of the suppression of the tertiary creep stage. This behaviour is particularly significant for industrial applications where designs are based on the creep life to a certain amount of creep strain such as $0.2 \%$ or $0.5 \%$ strain.

Creep fracture in both the CM and the DTM are predominantly intergranular. The differences in the $\mathrm{CM}$ and DTM lie in the cracking behaviour. The crack density is much higher in the CM than in the DTM material, Fig-9. In the CM, intergranular cracks develop very early during creep and the overall creep resistance of the material is poor. In the DTM. grain boundary sliding is hindered by a relatively coarser grain size and the presence of serrated grain boundaries. Cavity formation and coalescence are also delayed by the serrated grain boundaries due to their role in re-distributing the stresses. In addition, if vacancy diffusion distance to the grain boundaries is regarded as a rate controlling parameter for cavity nucleation and growth, the $\mathrm{CM}$ would be expected to have a higher cavity density than the DTM because of the finer grain size. Although the cavity link-up along the grain boundaries eventually leads to intergranular fracture in the DTM as well, the creep rupture life is substantially extended. The reduction in rupture strain in the DTM material is not totally unexpected because, in long term creep rupture tests, rupture strain is generally reduced due to longer exposure to an aggressive (oxidizing) test environment. 

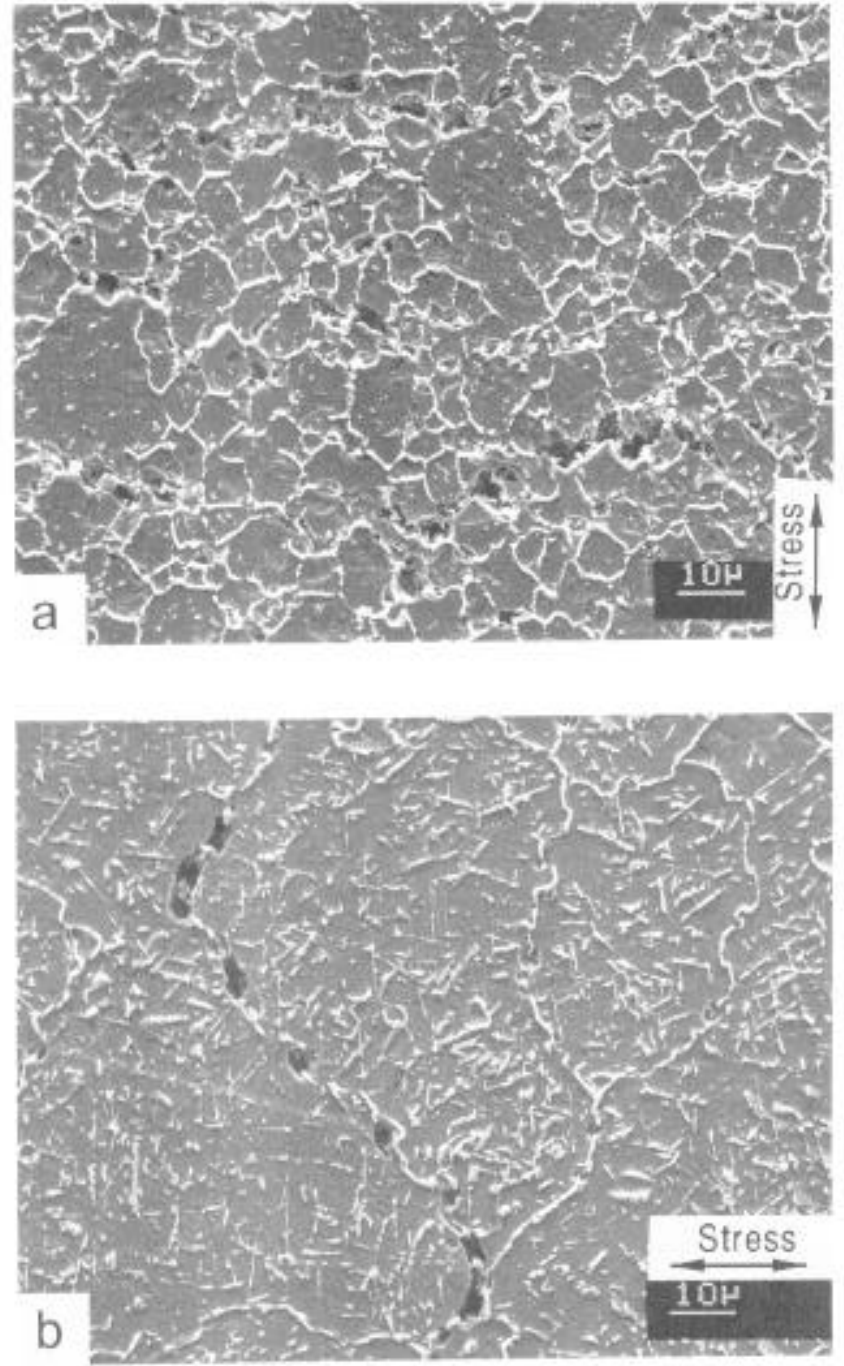

Fig-9. Creep cavities in both (a) CM and (b) DTM tested at $760^{\circ} \mathrm{C}$ and $350 \mathrm{MPa}$ in laboratory air.

The elevated temperature Fatigue Crack Growth Rate (FCGR) results of the two microstructures at two test frequencies of $1 \mathrm{~Hz} 0.15 \mathrm{~Hz}$ are compared in Figs 10 and 11 respectively. It is evident that the FCGRs of the CM and DTM are comparable at $1 \mathrm{~Hz}$ while the FCGR of the DTM is lower by a factor of 10 over a wide range of $\Delta K$ at a test frequency of $0.15 \mathrm{~Hz}$. It seems that there are two distinct Paris regimes in the CM as well as DTM at $1 \mathrm{~Hz}$, where the FCGR behaviour is represented by $d a d N=C \Delta K$ ", and the break point lies at $-45 \mathrm{MPa} \sqrt{\mathrm{m}}$. In contrast, at $0.15 \mathrm{~Hz}$, the slope $n$ is changing continuously in both microstructures and the $d a / d N$ versus $\Delta K$ eurves are bending down. Strictly speaking, the application of the Paris equation is limited to short $\Delta \mathcal{K}$ ranges in both cases.

The $n$ values at comparable $\Delta K$ ranges decrease with increasing frequency in both microstructures, Table-2, indicating a change in the contribution of different deformation mechanisms

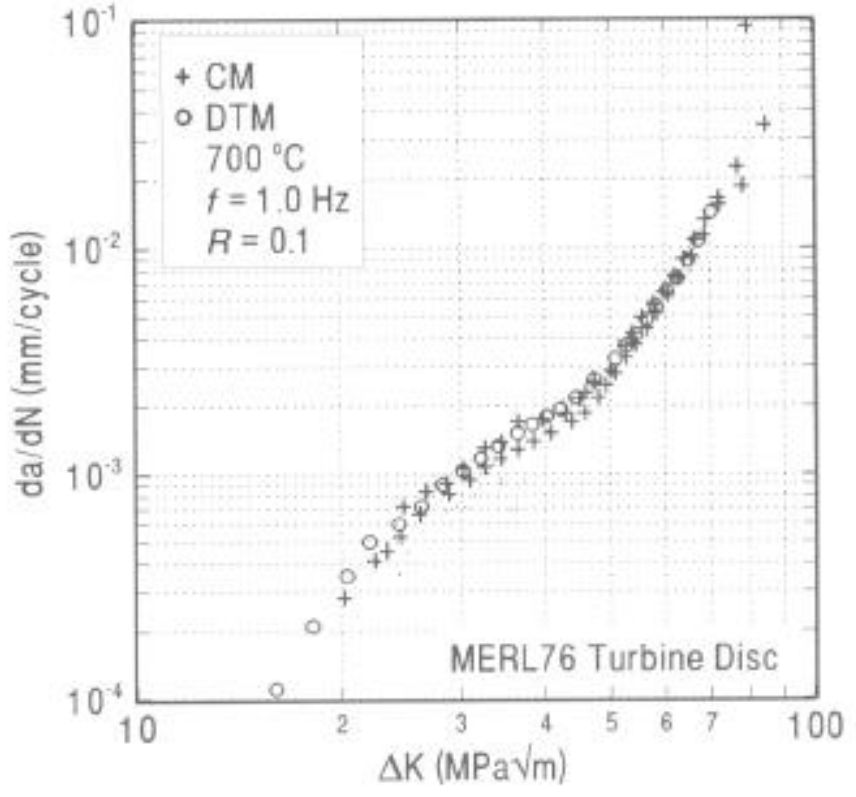

Fig-10. Comparison of FCGRs of CM and DTM at a frequency of $1 \mathrm{~Hz}$. tests conducted at $700^{\circ} \mathrm{C}$ in laboratory air.

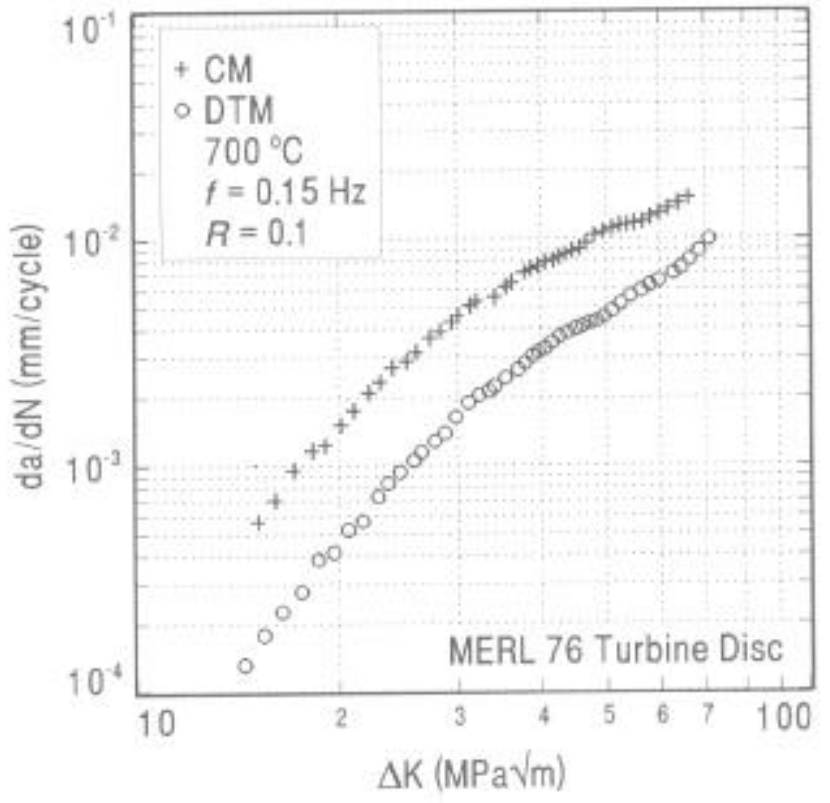

Fig-11. Comparison of FCGRs of CM and DTM at a frequency of $0.15 \mathrm{~Hz}$. Tests conducted at $700^{\circ} \mathrm{C}$ in laboratory air.

and grain boundary sliding assisted environmental attack within the plastic zone towards crack extension. This is because at lower frequencies the creep contribution towards crack growth increases. 
Table-2. Constants in Paris equation for MERL76 tests.

\begin{tabular}{|c|c|c|c|c|c|}
\hline \multirow[t]{2}{*}{ Frequency } & \multicolumn{2}{|c|}{$\mathrm{CM}$} & \multicolumn{2}{|c|}{ DTM } & \\
\hline & $n$ & $C$ & $n$ & C & \\
\hline \multirow[t]{2}{*}{$1.00 \mathrm{~Hz}$} & 2.7 & $0.9 \times 10^{-7}$ & 2.7 & $0.9 \times 10^{-2}$ & $\Delta K=20-40$ \\
\hline & 4.9 & $1.4 \times 10^{-11}$ & 4.9 & $1.4 \times 10^{-11}$ & $\Delta K=40-80$ \\
\hline \multirow[t]{2}{*}{$0.25 \mathrm{~Hz}$} & 3.0 & $1.1 \times 10^{-7}$ & 2.9 & $6.7 \times 10^{-3}$ & $\Delta K=15-40$ \\
\hline & 1.4 & $2.9 \times 10^{-5}$ & 1.8 & $3.3 \times 10^{-6}$ & $\Delta K=40-70$ \\
\hline \multirow[t]{2}{*}{$0.15 \mathrm{~Hz}$} & 2.9 & $2.5 \times 10^{-7}$ & 3.2 & $2.8 \times 10^{-k}$ & $\Delta K=15-30$ \\
\hline & 1.4 & $4.3 \times 10^{-5}$ & 1.9 & $2.8 \times 10^{-6}$ & $\Delta K=30-70$ \\
\hline
\end{tabular}

Note: $d a / d N$ in mm/cycle: $\Delta K$ in $\mathrm{MPa} \sqrt{\mathrm{m}}$.
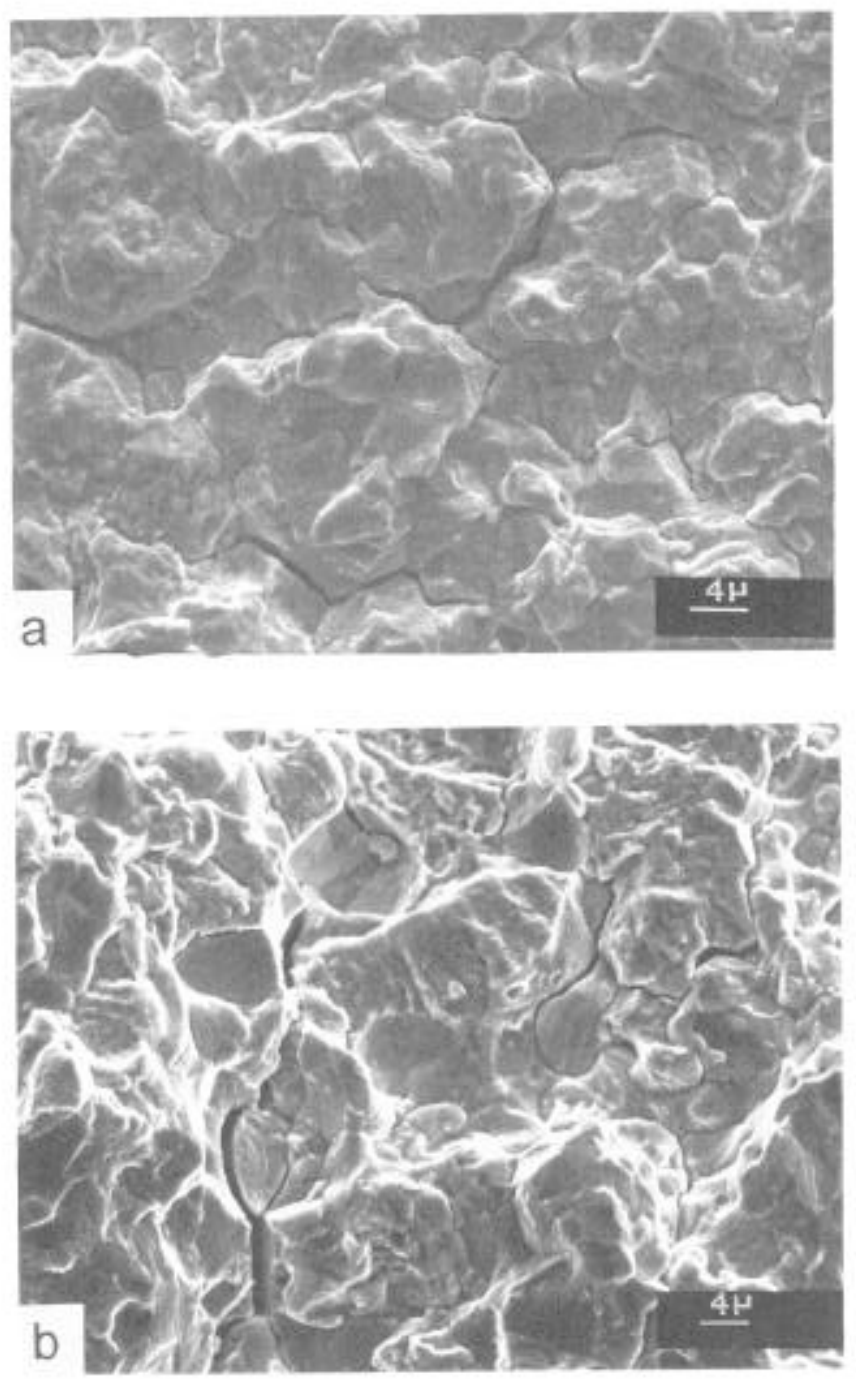

Fig-12. Fracture surface after FCGR tests in (a) CM and (b) DTM, at $700^{\circ} \mathrm{C}, 0.15 \mathrm{~Hz}$.
The fatigue fracture characteristics of the two microstructures at $700^{\circ} \mathrm{C}$ are somewhat different, Fig-12. In the $\mathrm{CM}$, intergranular crack propagation is observed over the entire range of $\Delta K$ studied. In contrast, a mixture of transgranular and intergranular crack propagation behaviour predominates in the DTM. This change in fracture bebaviour is considered to be the main reason for improved FCGR resistance of the DTM relative to the $\mathrm{CM}$. The presence of a larger area fraction of transgranular fracture in the DTM indicates suppression of grain boundary sliding and promotion of transgranular deformation within the plastic zone. This feature can be attributed to the presence of a coarser grain size and serrated grain boundaries in the DTM. In addition, the proportion of transgranular fracture also increases with increasing $\Delta K$ in the DTM.

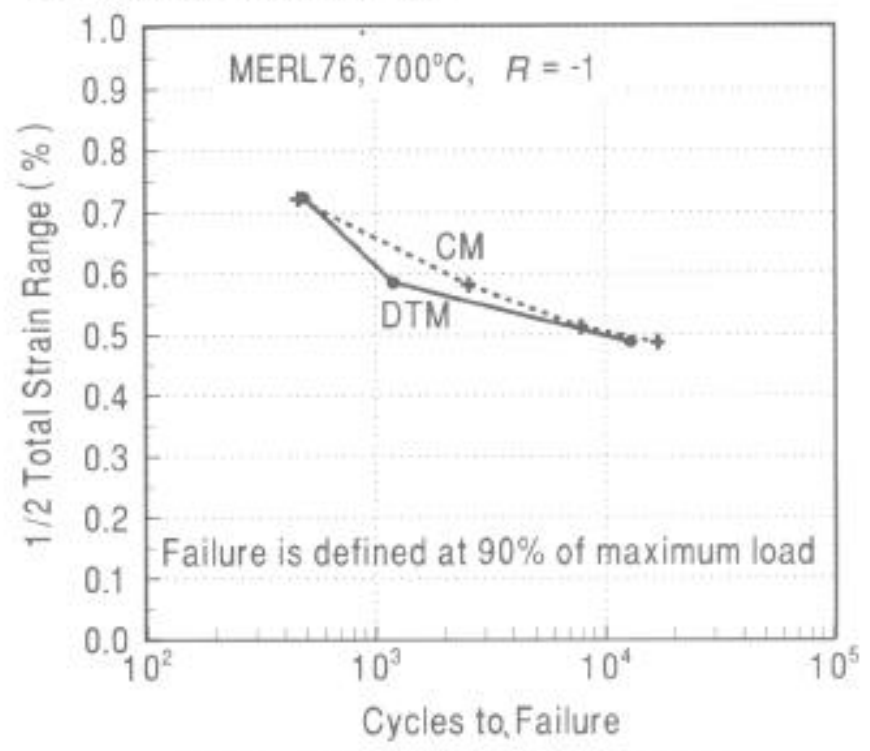

Fig-13. LCF life comparison between the two microstructures.

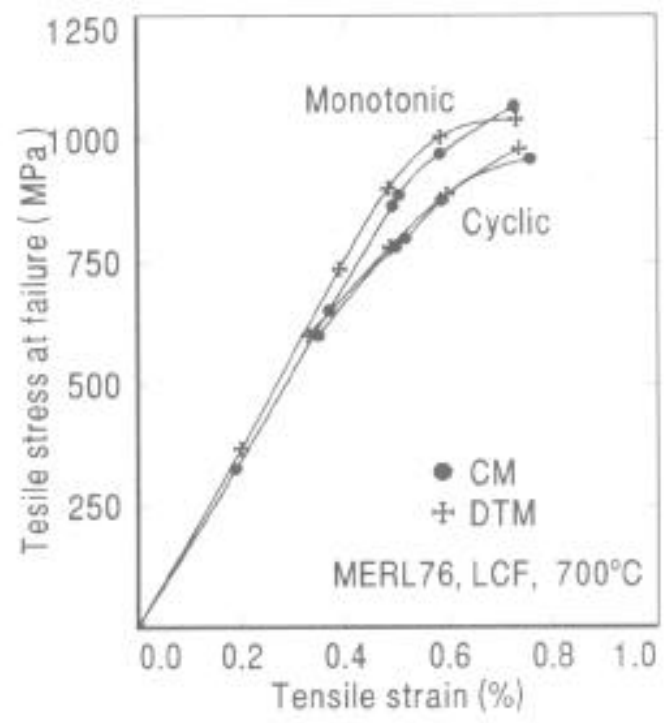

Fig-14. Comparison of monotonic and cyclic tensile stress in the two microstructures. 
The LCF crack initiation lives, as a function of total strain range, for both CM and DTM are compared in Fig-13. With the exception of one data point in Fig-13, the LCF lives of both microstructures are comparable at all strain ranges. The monotonic and cyclic stress-strain curves for the CM and DTM are compared in Fig-14. Both materials revealed cyclic softening with little apparent difference in the eyclic stress strain behaviour of the two microstructures.

Similar to tensile fracture, the LCF cracks initiate transgranularly or intergranularly near the specimen surfaces in both cases. A number of secondary cracks initiate on the specimen surfaces in both cases and they lie perpendicular to the tensile axis. The fracture surface characteristics of CM and DTM
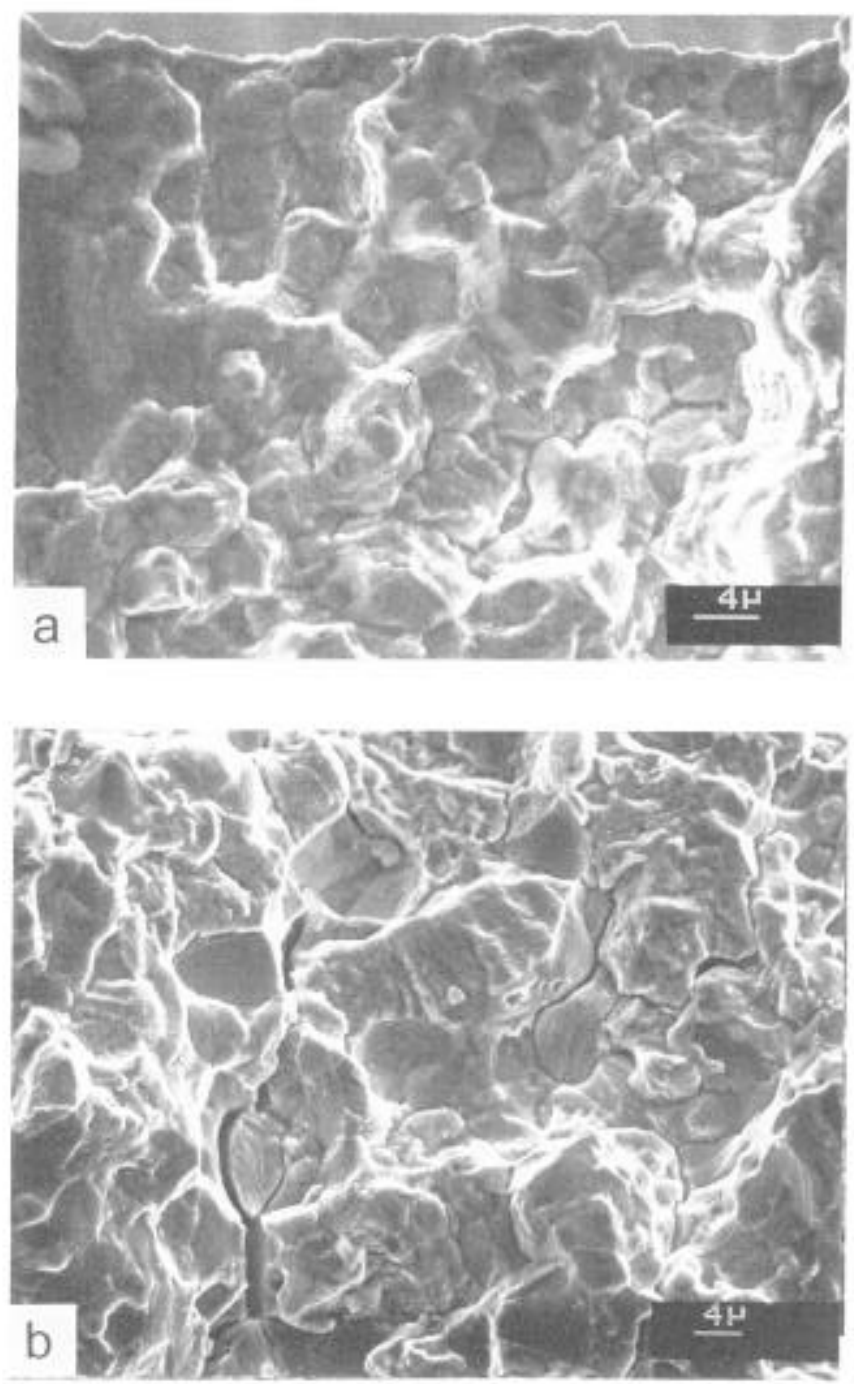

Fig-15. Crack initiation sites observed in LCF tests. a: CM, $\Delta \varepsilon_{\mathrm{t}}=0.974 \%, \quad N_{\mathrm{t}}=17000$ cycles. b: DTM, $\Delta \varepsilon_{t}=0.975 \%, N_{\mathrm{f}}=12900$ cycles. are compared in Fig-15. In the CM, crack propagation and secondary cracks are intergranular. In the DTM, the crack propagation oceurs in a mixed mode fashion. Also striations were observed in the DTM at a crack depth of about $0.5 \mathrm{~mm}$ from the crack initiation site. This feature was not observed in the CM.

Apart from concern about the loss in LCF life while designing the DTM, it is always important to ensure that the material is not rendered notch sensitive as a result of DTM. The LCF tests on notched Alloy 718 specimens have shown [19] that the DTM can produce longer crack initiation life than the CM.

\section{Conclusions}

A damage tolerant microstructure (DTM) has been designed for P/M MERL76 turbine disc material through super-solvus processing, furnace cooling from the solution treatment temperature followed by standard aging treatment. The DTM contains a uniform distribution of relatively coarser grain size than the conventional microstructure (CM) coupled with a serrated grain boundary structure. The primary as well as secondary $y^{\prime}$ distributions in the DTM are more uniform than in the CM. Based on the mechanical properties assessment and fracture surface examination, the following conclusions can be drawn:

1. Test results show that the DTM is indeed flaw tolerant undet different loading conditions including creep and fatigue loading conditions. In the DTM, a coarser grain size and the serrated grain boundaries are beneficial to both creep resistance and elevated temperature FCGRs. These mictostructural features were observed to suppress intergranular deformation and fracture and promote transgranular deformation and fracture

2. Creep rupture life of DTM is 9 times longer than the CM at a stress of $350 \mathrm{MPa}$.

3. At $700^{\circ} \mathrm{C}$, the FCGRs of the DTM are reduced by a factor of 10 over a wide range of $\Delta K$ at a frequency of $0.15 \mathrm{~Hz}$ relative to the CM whereas the FCGRs at a higher frequency of $1 \mathrm{~Hz}$ are similar. The serrated grain boundaries are believed to significantly contribute towards fatigue crack growth resistance at lower frequencies.

4. The LCF lives of the DTM and CM are similar over a wide range of strain range values but the yield strength of the DTM is lowered by about $7 \%$. 


\section{Acknowledgement}

This work was conducted under IAR-NRC project JHM05 with financial assistance provided by the Chief Research and Development, Department of National Defence, Canada, under financial arrangement 220794NRC05.

\section{References}

[1] MLL-STD-1783 (USAF): Military Standard, Engine Structural Integrity Program (ENSIP), by the Department of Defence, USA, Nov. 1984.

[2] MIL-STD-1843 (USAF): Military Standard, ReliabilityCentred Maintenance for Aircraft, Engine and Equipment, by the Department of Defence, USA, Feb. 1985.

[3] A.K.Koul, P.Au, N.Bellinger, R.Thamburaj, W.Wallace, and J-P. Immarigeon, "Development of a Damage Tolerant Microstructure for Inconel 718 Turbine Disc Material", SUPERALLOYS 1988, Ed. D.N.Duhl et al., TMS-AIME, 1988, 3-12.

[4] M.Chang, P.Au, T.Terada, and A.K.Koul, "Damage Tolerance of Alloy 718 Turbine Disc Materials", SUPERALLOYS 1992, Fd. S.D. Antolovich et al., TMSAIME, 1992, 447-456.

[5] J.Benson, K.Hunziker, and C.Williams, "Kejuvenation of Wrought IN-718 Diffuser Cases", SUPERALLOYS 1992, Ed. S.D.Antolovich, et al., TMS-AIME, 1992, 877883.

[6] D.D.Krueger, R.D.Kissinger, and R.G.Menzies, "Development and Introduction of a Damage Tolerant High Tempcrature Nickel-Base Disk Alloy, Rene'88DT", SUPERALLOYS 1992, Ed. S.D.Antolovich et al., TMSAIME, 1992, 277-286.

[7] JY.Guedou, JC.Lautridou, and Y.Honnorat, "N18, PM Superalloy for Disks: Development and Applications", SUPERALLOYS 1992, Ed. S.D.Antolovich et al., TMSAIME, 1992, 267-276.

[8] A.K.Koul, J-P.Immarigeon, and W.Wallace, "Microstructural Control in Ni-base Superalloys", Advances in High Temperature Structural Materials and Protective Coatings, book, Ed. A.K.Koul, et al., NRC publication, CANADA, 1994, 91-125.

[9] W.Wallace, A.K.Koul, J-P.Immarigeon, P.Au, and J.C.Beddoes, "PM Matures as Route to Aerospace Alloys", Metal Powder Reports, June 1994, p.32.

[10] J.II.Davidson, G.Raisson, and O.Fural, "The Industrial Development of a New PM Superalloy for Critical High Temperature Aeronautical Gas Turbine Components", Proceedings of Int. Conf. on PM Aerospace Materials, Lausanne, Switzerland, 1991, 2-1 - 2-12.
[11] D.J.Evans and R.D.Eng, "Development of a High Strength Hot Isostatically Pressed (HIP) Disk Alloy, MERL 76", Modern Developments in Powder Metallurgy, 14(1981), 51-63.

[12] R.H.Caless and D.F.Paulonis, "Development of Gatorized ${ }^{\circledR}$ MERL76 for Gas Turbine Disk Application", SUPERALLOYS 1988, Ed. by S.Reichman, et al., TMSAIME, 1988, 101-110.

[13] P.D.Genereux and D.F.Paulonis: "Nickel Base Superalloy Articles and Method for Making", European Patent, No. 0 $248757,1987$.

[14] K.-M.Chang and H.C.Fiedler, "Spray-Formed HighStrength Superalloys", SUPERALLOYS 1988, Ed. by S.Reichman, et al., TMS-AIME, 1988, 485-493.

[15] J.M.Hyzak and S.H.Reichman, "Forming of Advanced Nibase Superalloys", Advances in High Temperature Structural Materials and Protective Coatings, book, Ed. A.K.Koul, et al., NRC publication, CANADA, 1994, 126-146.

[16] T.C.Lu, O.Faral, Y.Bienvenu, and J.H.Davidson, "Study of the Evolution of the Microstructure of a Nickel Base Superalloy from the Atomised Powder to the Hip'ped Preform", Proceedings of Int. Conf. on PM Aerospace Materials, Lausanne, Switzerland, 1991, 5-1 - 5-11.

[17] A.K.Koul and G.H.Gessinger, "On the Mechanism of Serrated Grain Boundary Formation in Ni-Based Superalloys", Acta Met., 31(1983), 1061 1069.

[18] A.K.Koul and R.Thamburaj, "Serrated Grain Boundary Formation Potential of Ni-Based Superalloys and its Implications", Metall. Trans., 16^ (1985), 17-26.

[19] M.Chang, P.Au, T.Terada, and A.K.Koul, "Damage Tolerance of Wrought Alloy $718 \mathrm{Ni}$-Fe-Base Superalloy", J. of Mat. Eng. and Performance, 3(3)(1994), 356-366.

[20] L.N.Moskowitz, R.M.Pelloux, and N.J.Grant, "Properties of IN-100 Processed by Powder Metallurgy", SUPERALLOYS 1972, AIME, 1972, z-1 - z-25. 